\title{
Design and Prototype Testing of an Electric Drivetrain utilizing Electrochemical Capacitors
}

\author{
Michael Kiers, mtkiers@uwaterloo.ca; Dr. Mostafa Marei, Dr. Steven Lambert, Dr. Roy J. Pick, \\ Dr. M.M.A. Salama; Department of Mechanical Engineering and Department of Electrical and \\ Computer Engineering, University of Waterloo.
}

\begin{abstract}
This paper describes the design and development of a prototype electric drivetrain in preparation for the hybrid conversion of a passenger vehicle. The design is unique in that it utilizes an electrochemical capacitor bank for regenerative braking energy storage. The design focus is on the development of a control algorithm for the drive motor, and the development of high efficiency $D C-D C$ converters to interface the ultracapacitor bank, battery pack and motor controller.
\end{abstract}

\section{Introduction}

This paper describes the design and prototype refinement of a small scale electric vehicle drivetrain. The drivetrain has regenerative braking capability and energy storage in both a battery pack and an ultracapacitor bank. The main interest is in the design of energy efficient power electronics to interface the battery and ultracapacitors with the inverter. Another focus is the design of a control algorithm suitable for an automotive electric drive motor. A mechanical test bench was used to simulate vehicle load and evaluate the performance of electric and mechanical drivetrain components under vehicle acceleration and braking.

The use of ultracapacitors has not yet appeared on currently marketed hybrid vehicles, which have energy storage in battery packs only. Battery longevity has been found to be disappointing in current hybrids and battery packs often need to be replaced two or three times over the life of the vehicle. Also current hybrids are limited in their regenerative braking power, as the small battery packs are incapable of handling the high power. An ultracapacitor bank used in conjunction with a battery pack has the potential to lengthen battery life and increase regenerative braking capability. Since braking is a frequent high power event, utilizing ultracapacitors to capture this energy reduces degenerative high power battery cycling.

This project was initiated to study hybrid vehicle drivetrain design, and to build a team with mechanical and electrical engineering expertise for the future design project of a full scale gasoline-electric hybrid vehicle.

A constraint on the electrical design in this project was that it be scaleable to the power level of a road vehicle, to ensure that the design knowledge would be applicable to the future project. An approximate $1 / 100^{\text {th }}$ scale was chosen. The drivetrain and test bench load were sized based on a $150 \mathrm{~kW}$ peak power vehicle, representative of a minivan or small SUV.

\section{Ultracapacitor Technology}

Ultracapacitors are a remarkable advance in capacitor technology, as large cell units ( $\sim 0.5 \mathrm{~L}$ volume) may be rated at over 3000 Farads. The energy storage mechanism is electrostatic, as in a conventional capacitor, but the electrode is a very high surface area material. One commonly used material is activated carbon, which has a low density structure filled with micro-pores (Figure 1). The electrode is covered in a liquid ionic electrolyte which neutralizes the electron excess or deficiency at the electrodes, through formation of a double-layer of ionic and electron charge at the wall surfaces of the pores.

The capacitance of a cell is proportional to the electrode surface area, and an activated carbon electrode may have a surface area as high as $2000 \mathrm{~m}^{2} / \mathrm{g}$. Capacitance is also inversely proportional to the distance between the plates, and the electrolyte and electrode interface is separated by a 0.3 to $0.5 \mathrm{~nm}$ boundary layer of electrolyte solvent. A specific energy storage capacity of $250 \mathrm{~J} / \mathrm{g}$ is theoretically possible at a $1 \mathrm{~V}$ potential, although less than a quarter of this is practically realizable [1].

Fundamentally different from ultracapacitors, energy storage in batteries is Faradaic and relies on chemical 
reduction and oxidation reactions and phase changes at the electrodes. Thus battery energy storage density (i.e. $\mathrm{J} / \mathrm{g}$ ) is high, typically 10 times more than in ultracapacitors. However due to the limitations of these chemical reactions and electrolyte diffusion, the power density is limited in batteries.

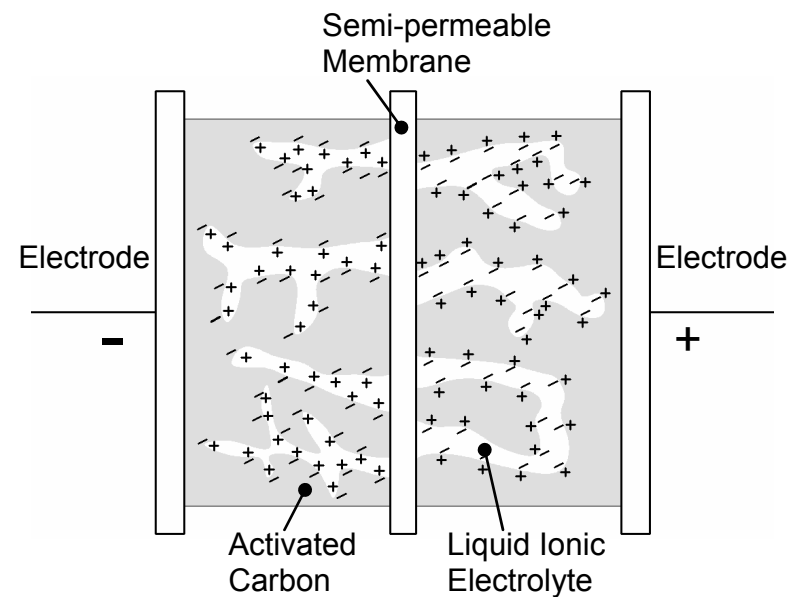

Figure 1. Ultracapacitor Design [1]

Ultracapacitor energy storage is electrostatic; no chemical reactions occur and no atoms pass through the boundary layer. The power delivery is therefore only limited by the viscosity of the electrolyte, which limits the response time of the ionic solution under an applied electric potential field. The power density of an ultracapacitor is typically 10 times greater than a battery.

A further benefit of the ultracapacitor non-Faradaic energy storage mechanism is that cell life is on the order of $10^{5}-10^{6}$ cycles; a battery is limited to the $10^{2}$ $-10^{3}$ cycle range [1].

Ultracapacitor technology is new, and it has mainly been used in small electronic devices with intermittent high power requirements, such as digital cameras, personal digital assistants and pagers. Their use in conjunction with a battery pack lengthens battery life and reduces pack size. Larger cells have found use in high-power actuators, wind turbine power back-up, large diesel engine starters, power quality correction devices, helicopter airbags and uninterruptible power supply units. These applications are characterized as servicing high-power events, and require a long cycle life.

\section{Drivetrain Components}

The model drivetrain (Figure 2) consists of a drive motor with controller, a battery pack, an ultracapacitor bank, and two DC-DC converters. The converters are necessary to interface the lower voltage energy sources with the high voltage motor controller. A DSP is used to control the inverter and to coordinate the DC-DC converters with the motor controller. This component layout and interaction is identical to that which may be used in a series or parallel hybrid vehicle. A flywheel was used to provide drivetrain load.

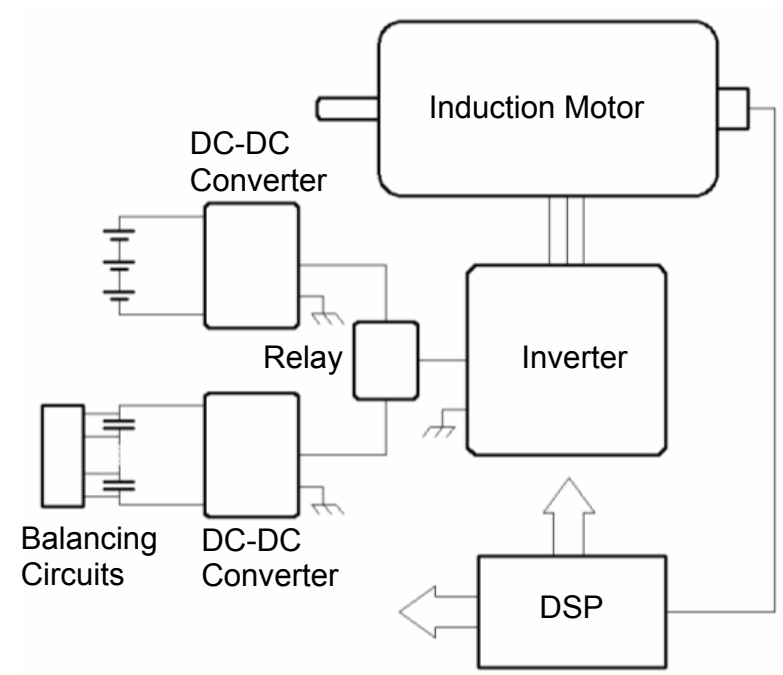

Figure 2. Electric Drivetrain Layout

A three-phase Baldor $1.5 \mathrm{~kW}$ AC induction machine was chosen as the drive motor; an approximate $1 / 100^{\text {th }}$ fraction of the peak engine power in a typical minivan or small SUV. The motor inverter hardware is a $1.5 \mathrm{~kW}$ board from Spectrum Digital (DMC 1500). The controller has a DC bus voltage of $300 \mathrm{~V}$. Three automotive accessory batteries (12V nominal) were put in series to provide a $36 \mathrm{~V}$ source. Fifteen Maxwell $2500 \mathrm{~F} 2.5 \mathrm{~V}$ cells make up the ultracapacitor bank, again connected in series to provide a $37.5 \mathrm{~V}$ max source. To interface the batteries and ultracapacitors to the inverter, two bi-directional buck-boost DC-DC converters were required. In addition the converter interface to the ultracapacitor bank had to accept a variable 0 to 37.5 input voltage level to account for the variation in the ultracapacitor state of charge (the battery has an approximately constant voltage). The hardware boards and inductor coils were custom built, along with the software controls, for this specific application.

An electronic relay was used to control the energy flow between the batteries and ultracapacitors. The ultracapacitor pack was strictly used for storing energy from regenerative braking, and subsequent acceleration of the flywheel. The ultracapacitor pack was never allowed to fall below $1 / 2$ of the rated voltage (1/4 energy storage). 
To control the inverter and the DC-DC converters, a DSP evaluation kit, for the Texas Instruments processor TMS320LF2407A, was purchased. The rotor speed is fed into the DSP from the motor tachometer to give a closed loop circuit.

To test the powertrain performance, a suitable test bench load was attached. Since it is of interest to examine powertrain performance under the most stressful operating conditions, i.e. rapid acceleration and peak deceleration, the aerodynamic and rolling resistance losses were ignored in sizing the test bench load. A large steel flywheel (Figure 3) was chosen to simulate $1 \%$ of the effective inertia of a 2003 Chrysler Voyager minivan. The flywheel has an inertia of $2.28 \mathrm{~kg} \cdot \mathrm{m}^{2}$.

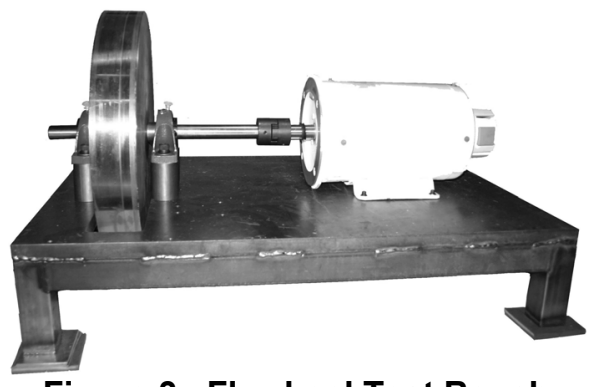

Figure 3. Flywheel Test Bench

A large steel frame was constructed to mount the motor and flywheel, providing a stable base for the dynamic operation of the unit.

\section{Electric Drive Control Algorithm}

There are many types of machines that can be used as electric drive motors. The squirrel cage induction motor was selected as its simple design is inexpensive to manufacture and very robust.

A drive motor requires fast torque response and fourquadrant operation. The electrical machine must provide maximum torque near zero speed and a controlled torque over a wide range of operating conditions. To implement these requirements the following control characteristics are necessary:

- An independently controlled armature current to overcome the effects of winding resistance, leakage reactance and emf, and to give a constant field flux magnitude.

- An independently controlled or constant value of the field flux.

- An independently controlled orthogonal spatial angle between the flux axis and the mmf axis to avoid interaction between them.
If these requirements are met, the torque will immediately follow the current and instantaneous torque control will result.

Many schemes have been proposed for the control of induction motor drives. Vector control has gained the widest acceptance in high performance applications such as electric vehicles. Through this method, control of the highly coupled, nonlinear, multivariable induction motor is reduced to linear independent flux and torque control, similar to that of a separately excited DC motor. The advantage of this method is that it maximizes the torque per ampere capability of the machine. Figure 4 shows the implemented control block diagram.

To simplify the control variables in Vector control, a reference frame that synchronously rotates with the field flux is usually chosen. To resemble separately excited DC motor control, the field flux vector is aligned with the direct axis and the torque producing component of the stator current is aligned with the quadrature axis, to allow independent control of flux and torque. These control parameters are then transformed back to the stationary reference frame and to three phase motor currents [2].

To implement a high performance drive, the inverter design has a very important role. It should force the actual current to follow the reference current as accurately as possible to guarantee decoupled torque and flux control. A Current Regulated Pulse Width Modulated inverter (CRPWM) has operating characteristics similar to both a current source and a voltage source inverter. A current source inverter (CSI) operates very well at low speeds, where machine counter emf is low, and the current controller will track well. But at a higher speed, the current controller will tend to saturate during part of the cycle because of a high counter emf. Although a voltage source inverter (VSI) tends to perform poorly at low speeds, it works better as the speed increases. The CRPWM eliminates these problems by acting as a hybrid of the two types; it retains the good low speed performance of the CSI and the good high-speed performance of the VSI.

Various current controller strategies have been developed [3]. The control algorithm switching technique requires quick response, high current limit, insensitivity to load parameter variations and easy implementation.

Space Vector Modulation (SVM) was implemented as it satisfies these requirements. In addition SVM insures the lowest switching frequency and current error compared to other current controllers [4]. 


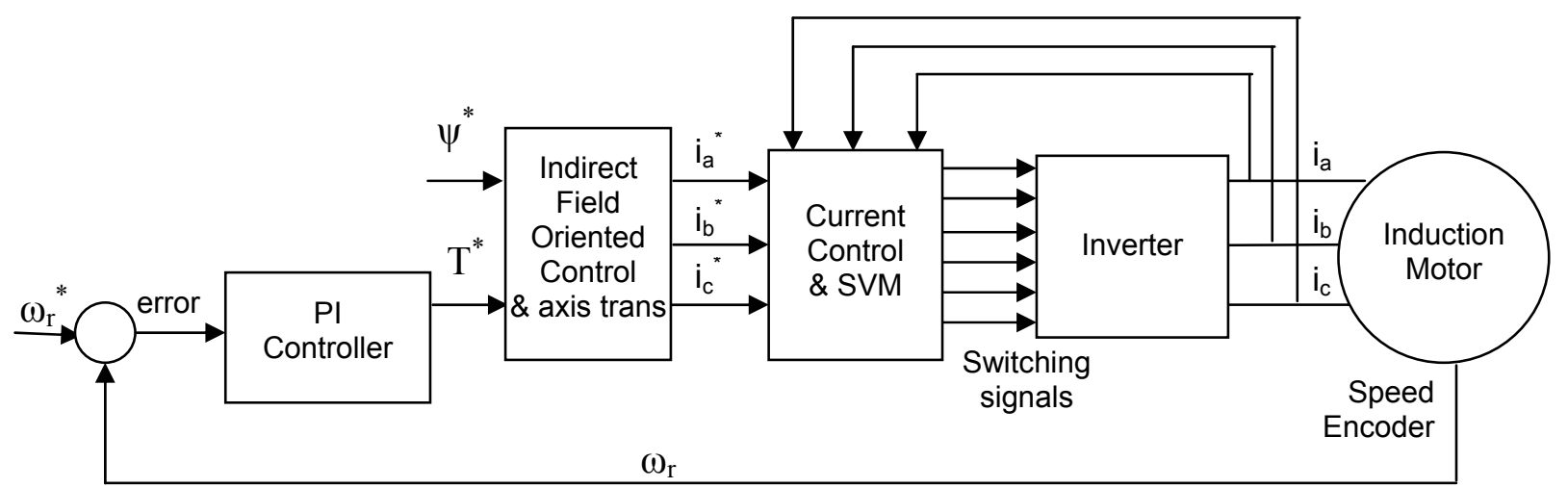

Figure 4. Motor Vector Control Schematic

\section{DC-DC Converter}

Whereas the motor control hardware and software are relatively established technologies, there is little availability of DC-DC converters with bi-directional and buck-boost capability for the voltage level required in this system. One company that produces a similar unit is Solectria; however it was found that the required flexibility and voltage levels were not available, and that the price was prohibitive for this project.

The parameters for the design were that the units have a low hardware component cost and be completely scaleable to full vehicle power. The power circuit is shown in Figure 5. This circuit actually consists of two identical circuits connected in series; a low voltage side boosts to an intermediate $80 \mathrm{~V}$ level, and the high voltage side further raises the voltage to $300 \mathrm{~V}$. Each circuit has only two power transistors, compared to a transformer design with eight transistors. A transistor is the most expensive component in a high power inverter. This design is easily scaleable to full vehicle power.

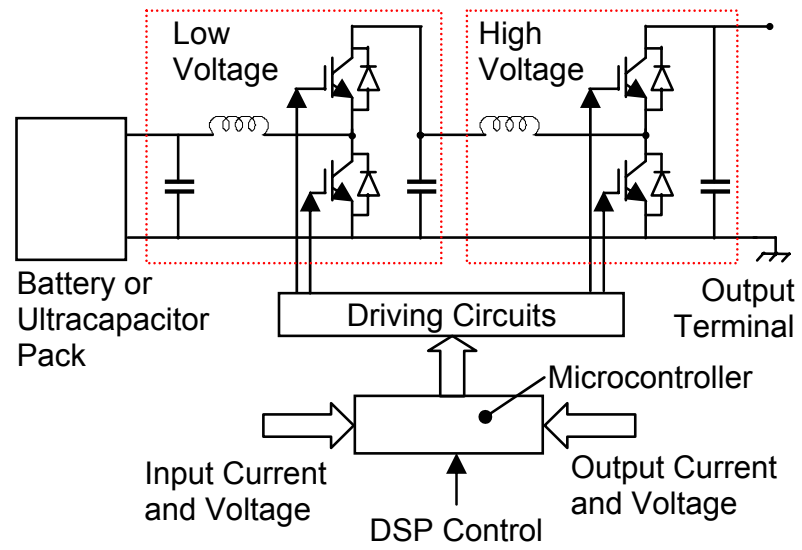

Figure 5. Converter Hardware Schematic
A microcontroller controls the unit, with feedback signals of input and output current and voltage to form a closed loop algorithm.

During boost-mode operation (vehicle acceleration and/or constant speed driving) the unit uses a voltage control loop, where the switching of the transistors is controlled to create the required voltage across the inductors and consequently at the output terminals. The control block diagram for either stage of the DC/DC converter is shown in Figure 6.

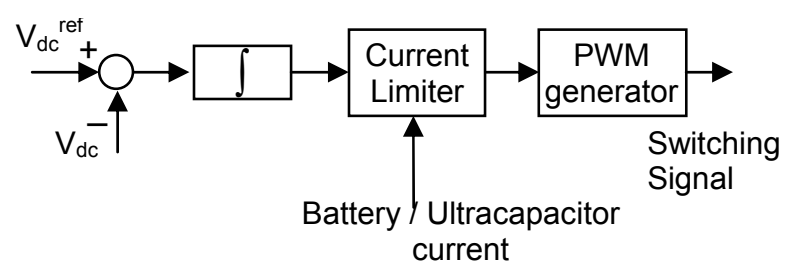

Figure 6. DC/DC Converter Control

\section{Results}

It was found that the efficiency of the motor controller was very high, over $95 \%$. However the efficiency of the motor itself ranged from $70-80 \%$, limited by the inherent induction motor inefficiency at low operating speeds.

The measured efficiency of the converter in boost mode for different power levels is shown in Figure 7. The peak efficiency is $77 \%$. One can see that the higher power tests have a greater efficiency; which can be attributed to the fact that most of the losses are hysterisis and eddy current core losses in the inductors. The measured core losses from an open circuit test (no load) were $150 \mathrm{~W}$. The core losses are proportional only to frequency and voltage; therefore they remain constant throughout the operating range. The copper losses $\left(I^{2} R\right)$ accounted for only $35 \mathrm{~W}$ maximum. 


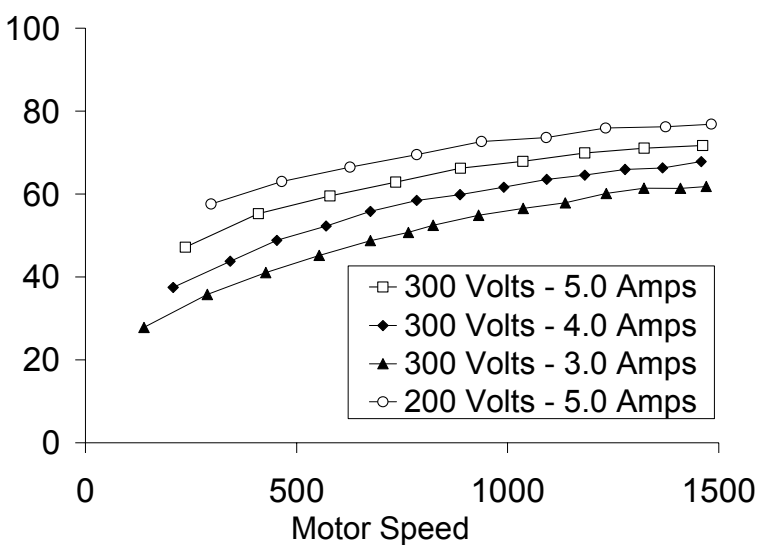

Figure 7. Converter Boost Mode Efficiency

Core losses can be reduced by lowering the voltage step, thereby decreasing transistor switching frequency, redesigning the inductors to reduce eddy currents, or choosing a different material to reduce hysterisis inefficiencies.

When the vehicle performs regenerative braking, the converters must channel the power back into the ultracapacitors. To complicate the design, the induction motor does not have a self-excited field; therefore power must be supplied to the stator winding during braking to create the necessary field.

It is possible that the stored energy in the ultracapacitor bank may be too low to supply the braking field. This is not necessarily due to energy mismanagement. Ultracapacitors have an inherent self-discharge mechanism, termed leakage current, which drains their energy if the vehicle is parked for a significant amount of time. In this situation it may be necessary to supply power to the braking field from the battery rather than the ultracapacitor pack, if the charge of the ultracapacitor bank is low. Subsequently the power flow must be reversed into the ultracapacitor bank.

If the regeneration energy is channeled through a buck converter, there will be an associated inefficiency, on the same scale as in boost mode. Since the ultracapacitors have a high current rating of $625 \mathrm{~A}$, current control during braking (charging) is not a requirement. Therefore it was found that a simplified buck mode could be utilized; essentially the ultracapacitors could be directly connected during regeneration, as soon as substantial reverse power flow was detected. It requires a minimum voltage in the ultracapacitors to allow the inverter, which is operating at the lowered voltage, to follow the requested brake torque / current demand.

This regeneration circuit was implemented via an electronic relay in parallel with the converter. When required the relay would switch, causing direct power flow into the ultracapacitor bank at essentially zero losses.

\section{Conclusions}

This design and development project was invaluable in creating the knowledge base for the future development of a hybrid passenger vehicle. It was found that the greatest challenge in the system was reducing the losses of the DC-DC converter. Different inductor core materials and inductor designs will be tried to minimize hysterisis and eddy current core losses. Additionally the large voltage differences in the system do not permit a high operating efficiency for the topology chosen. In the full vehicle the voltage difference between the energy sources and the motor should be minimized. For regenerative braking, the use of a direct connection to the ultracapacitors was found to effectively increase regeneration efficiency.

\section{References}

[1] B.E. Conway, Electrochemical Supercapacitors: Scientific Fundamentals and Technological Applications, Kluwer Academic / Plenum Publishers, New York, 1999.

[2] Peter Vas, Vector Control of AC Machines, Oxford: clarendon press, 1990.

[3] W. Leonhard, Control of Electrical Drives, Springer Verlag, New York, 1996.

[4] M. P. Kazamierkowski and W. Sulkowski, "A Novel Vector Control Scheme for Transistor PWM Inverter-Fed Induction Motor Drive," IEEE Transaction on Industrial Electronics, Vol. 38, No. 1, Feb 1991, pp. 41-47. 